\section{Exciting advancements in ovarian cancer treatment}

\begin{tabular}{|c|c|c|}
\hline $\begin{array}{l}\text { Ovarian cancer is treacherous } \\
\text { and challenging to treat. With } \\
\text { standard treatment unchanged } \\
\text { since the } 1990 \text { s and newer costly } \\
\text { treatments failing to restrain } \\
\text { the tumour's growth over long } \\
\text { periods of time, an overhaul in } \\
\text { anti-cancer treatment is urgently } \\
\text { needed. With fresh insights into } \\
\text { the biology and progression of } \\
\text { ovarian cancer, Lev Ashraphyan, } \\
\text { Vsevolod Kiselev from Institute } \\
\text { of Gynecologic Oncology } \\
\text { and Mammology of Acad. } \\
\text { VII.Kulakov National Medical } \\
\text { Research Centre of Obstetrics, } \\
\text { Gynecology and Perinatology, } \\
\text { the Ministry of Health of Russia, } \\
\text { and Ekaterina Muyzhnek } \\
\text { from the pharmaceutical } \\
\text { company, Ilmix Group, and } \\
\text { Gennady Sukhikh from Acad. } \\
\text { VII.Kulakov National Medical } \\
\text { Research Centre of Obstetrics, } \\
\text { Gynecology and Perinatology, } \\
\text { the Ministry of Health of Russia } \\
\text { have uncovered a promising } \\
\text { new treatment. }\end{array}$ & $\begin{array}{l}\text { varian cancer is treacherous } \\
\text { and crafty. Laying low and } \\
\text { silently spreading, the tumour } \\
\text { thrives undetected. When it's finallly } \\
\text { identified the tumour is often advanced } \\
\text { and is a formidable challenge to treat. } \\
\text { Its aggressiveness leaves women with } \\
\text { a five year survival rate of anywhere } \\
\text { between } 12-42 \% \text {, taking } 150,000 \\
\text { lives annuallly worldwide. For this, it is } \\
\text { known as the 'Silent Killer'. A promising } \\
\text { new therapy for this cruel cancer has } \\
\text { been developed by clinicians and } \\
\text { scientists including Academician of } \\
\text { the Russian Academy of Sciences, } \\
\text { Prof Lev Ashraphyan and Associate } \\
\text { academician of the Russian Academy } \\
\text { of Sciences, Prof Vsevolod Kiselev from } \\
\text { Institute of Gynecologic Oncology and } \\
\text { Mammology of Acad. VI.I.Kulakov National } \\
\text { Medical Research Centre of Obstetrics, } \\
\text { Gynecology and Perinatologyy, the } \\
\text { Ministry of Health of Russia; D Ekaterina } \\
\text { Muyzhnek from the pharmaceutical } \\
\text { company, IlmixGroup, and Academician } \\
\text { of the Russian Academy of Sciences, Prof }\end{array}$ & $\begin{array}{l}\text { Gennady Sukhikh from Acad. VI.IKulakov } \\
\text { National Medical Research Centre of } \\
\text { Obstetrics, Gynecology and Perinatology, } \\
\text { the Ministry of Health of Russia. } \\
\text { TENACIOUS TUMOURS } \\
\text { Treatment for ovarian cancer has } \\
\text { changed little since the late 1990s. } \\
\text { The standard treatment involves surgery } \\
\text { to remove as much of the tumour as } \\
\text { possible (maximal cytoreductive surgery) } \\
\text { followed by a cocktail of platinum-based } \\
\text { drugs and taxanes (chemotherapy), } \\
\text { aimed at killing cancer cells. One } \\
\text { would think that attacking the tumour } \\
\text { from all angles would wipe it out for } \\
\text { good, yet this is not the case. Within } \\
6-24 \text { months after the treatment, } \\
60-80 \% \text { of patients relapse and further } \\
\text { cycles of chemotherapy are required. } \\
\text { Unfortunately, chemotherapy doesn't kill } \\
\text { all the cancer cells, some are resistant to } \\
\text { the drugs. When a drug attempts to kill } \\
\text { a cancer cell, it has no effect on resistant } \\
\text { cancer re elll and they stay alive. Once } \\
\text { the resistant cells start multiplying they }\end{array}$ \\
\hline
\end{tabular}

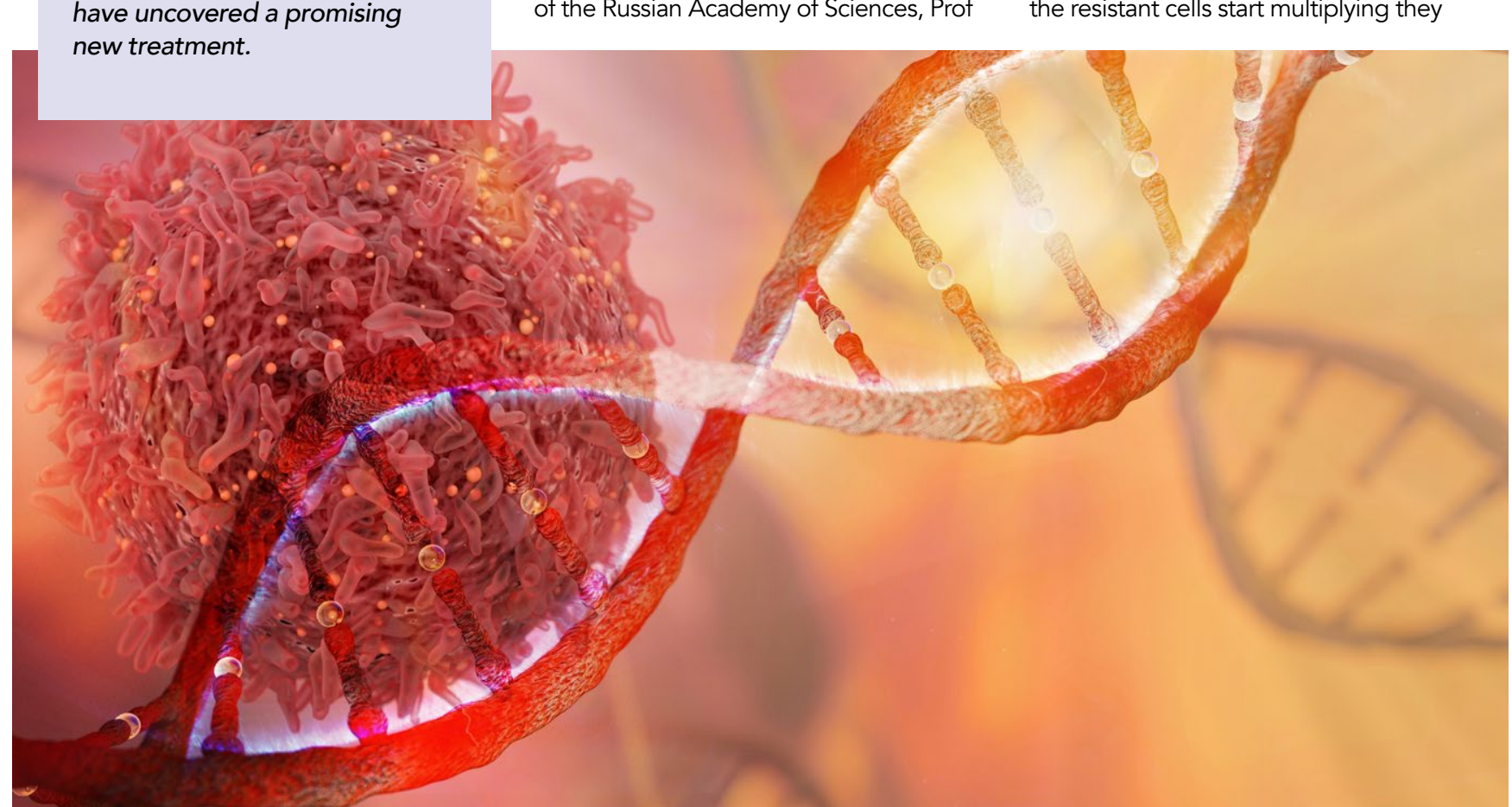

form chemoresistant tumours, whichs can't be destroyed, leading to medica The need for more lf leaths. has never been more urgent.

In recent years, targeted anti-tumour drugs known as 'Breakthrough Therapies' have been made widely available. With a catch phrase like that we should all be jumping for joy. For some, targeted therapy has helped extend patient's lives for months, this is viewed as a success, as success is often measured in days. This truly sounds like a breakthrough so why is there a growing scepticism about targeted therapies amongst researchers and clinicians?

Imagine this, you have a rubbish bin in your house but you don't understa filling it with rubbish. As the pile gets bigger you squash it down and pack it in, trying to contain it, but one day you know that if you don't figure out the collection day the rubbish will take over your house. Now, imagine the rubbish bin is a tumour and the human trying to control the waste is the targeted therapy. According to the original vision, targeted therapies aimed to decrease tumour size and eventually, eliminate the tumour. Actually, it turns out that targeted therapies are unable to get rid of the tumour. The main positive effect of targeted drugs is usually less about decreasing tumour size than achieving management process Like the hum not understanding collection days, if scientists don't figure out how to get rid of the tumour, or rather to remove tumour's source (its root system) instead of reducing its size, the patient could relapse. Another drawback is that over time, tumours develop resistance to the monotargeted drugs, just like their predecessors, so the positive effects don't last long. Targeted therapies cannot be used alone or even in combination with convention chemotherapy to effectively fight ovarian cancer. For the next generation of cancer therapies, a better understanding of chemoresistant and recurrent ovarian tumours is needed

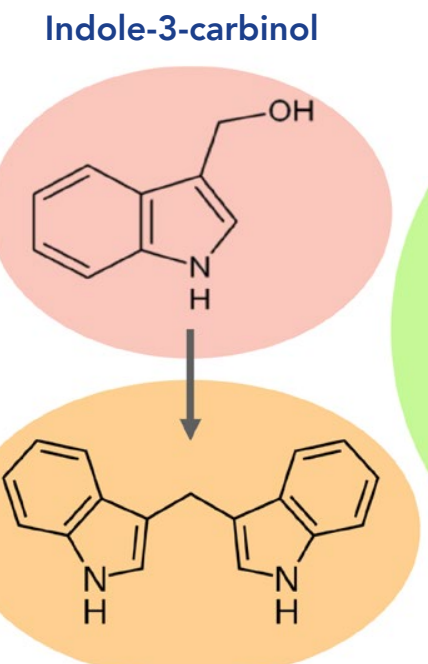

3,3'-Diindolylmenthane

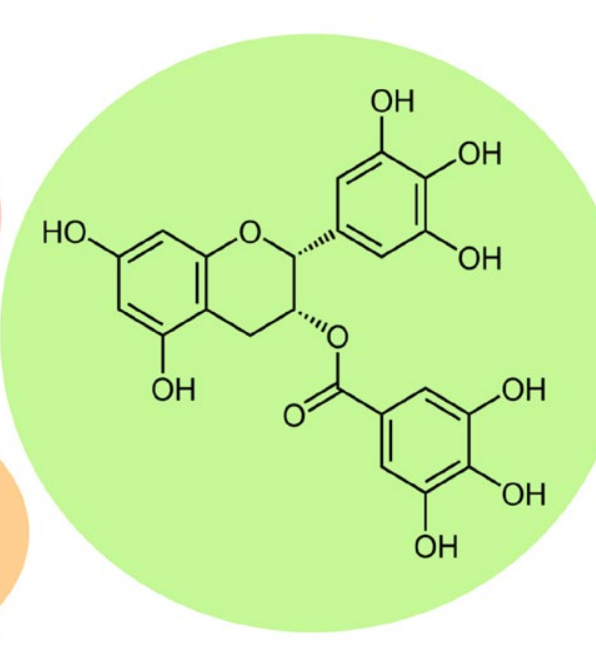

Epigallocatechin-3-gallate
Figure 1: Indole-3-carbinol, 3,3'-dindolylmethane, and epigallocatechin-3-gallate: chemical structure

\section{THE NEXT CHAPTER}

It's not all doom and gloom. In recent

to understand tumour recurrence

and resistance. A recent scientific

breakthrough in cancer research involves

the discovery of a population of hardy

cancer cells, known as cancer stem

cells, or CSCs. Research into this rare

population of immortal cells suggests

they are responsible for chemoresistance

and recurrent tumours in many different

There are also lots of CSCs in ascites (the abnormal buildup of fluid in the advanced ovarian cancer and its relapse. However, if the patients are treated with CSCs inhibitors during the chemotherapy this may reduce or prevent recurrence and even promote patient survival.

It's about time anti-cancer therapy started a new chapter. Equipped with a greater understanding of tumour chemoresistance

Its aggressiveness leaves women with a five year survival rate of anywhere between 12-42\%, taking 150,000 lives annually worldwide.

discovery has opened up a whole new
opportunity for cancer research scientists,
who over the last decade, have been
searching and developing new drugs
to destroy CSCs.
Astonishing findings reveal that
combining conventional chemotherapy
with ovarian CSCs inhibitors is essential
for tackling the tumour. In the first
round of chemotherapy the bulk of
ovarian tumour cells are eliminated
but hardy, chemoresistant CSCs survive
the treatment. While the symptoms for
the patient disappear, CSCs silently grow
into tumours. At recurrence the patients
have large tumours full of CSCs that
cannot be destroyed with chemotherapy.

can begin to uncover more effective anticancer treatments.

BACK TO NATURE Today, natural agents play a dominant role in the discovery of leads for the
development of drugs against many human diseases, especially cancer. Currently, over $60 \%$ of anti-cancer drugs are derived in one way or another from natural sources, with the rest being artificially synthetised.

In the recent study led by Academicians Lev Ashraphyan and Vsevolod Kiselev and their colleagues, compounds of to identify their effectiveness in treating 
advanced ovarian cancer. Indoles - indole-Carbinol (IIC), 3,3-dinndolylmethane 3-gallate (EGCG) are the rock stars of anticancer treatment and widely called "a therapeutic manel". Their humble origins in cruciferous vegetables, including sprouts, and green tea has not set them back. These natural substances have been comprehensively studied in various cancers, including ovarian cancer, and have unique anti-cancer properties.

In contrast to monotargeted drugs that hit only one molecular target of the tumour for some time, these compounds possess multiple antitumour activity and attack cancers simultaneously from multiple angles. They stop tumour cells from growing cells to die. They fight off molecules important for fuelling cancer cell grow and spread including agcressive estrogens, inflammatory molecules, oxidants, growth factors Incredibly, they are also capable of inhibiting CSCS by inducing their death and blocking key pathways responsible for their aggressiveness and chemoresistance. All these activities, including developmen of chemoresistance, are being implemented by reversible epigenetic mechanisms changing gene expression. All three above natural substances have demostrated epigenetic anttumour activity

In the study, these substances were used in the form of the medical drug Indinol ${ }^{\circledast}$ (both MiraxBioPharma, Joint-Stock Company. Russia) manufactured under a special technology according to current GMP standards. Unique properties like this make these agents an excellent contender for the next generation of anticancer treatments.

\section{LIGHT IN THE DARK}

In a first of its kind clinical trial conducted by the research team, 284 women with untreated advanced ovarian cancer were assigned maintenance therapy with orally administered $\mathrm{I} 3 \mathrm{C}$ as well as $\mathrm{ISC}$ with EGCG as Indinol forto and Promisan pharmaceutical agents. Maintenan therapy was administered before, during, and for five years after combined

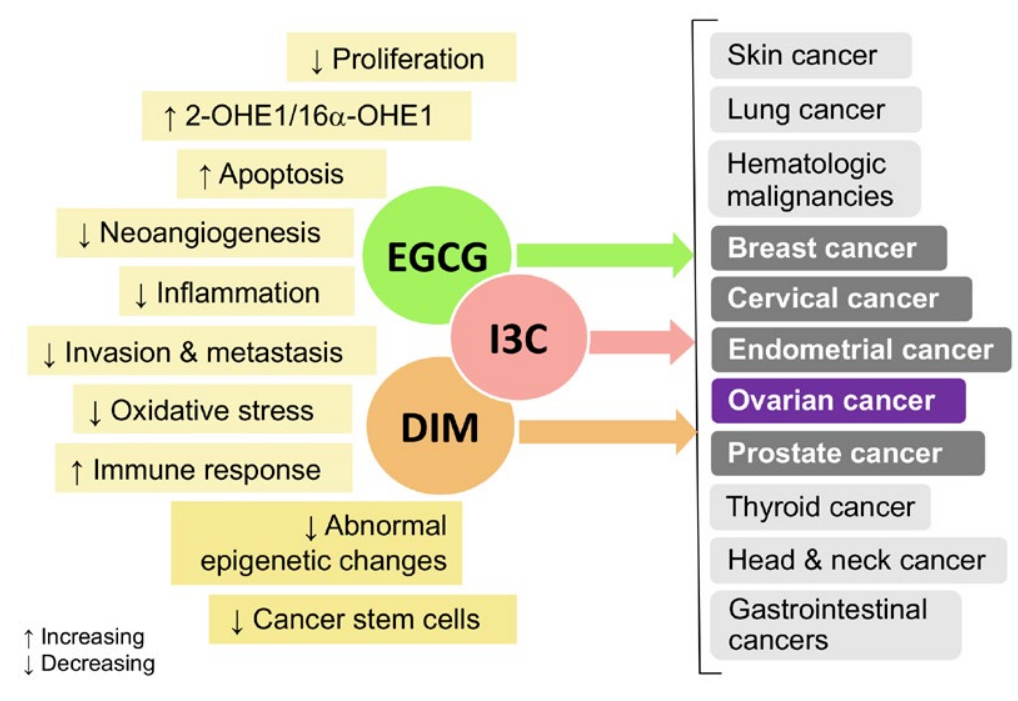

Figure 2: Multiple anti-cancer activity of indole-3-carbinol (IIC), 3,3'-dindolylmethane (DIM),
and epigallociptechin -3 -

to remove the tumour). The results were shocking. Maintenance therapy with $13 \mathrm{C}$ dramatically increased median cancer sunival by almost one and a half times over five years and 5 -year overall sunviva increased from $37 \%$ to $67 \%$.

What's more, researchers found patients were living longer without the tumour getting worse and there was a dramatic reduction in relapses with ascites. A huge benefit was identified from taking agents based on $\mathrm{ICC}$ and EGCG along with chemothera prior to surgery; in these patients, surgeon

daily activities. In addition, these drugs do not demonstrate any significant have no additional side effects. This safe approach to treating ovarian cancer is also inexpensive and affordable. Current anti-cancer therapies can cost anywhere from $\$ 10,000$ - $\$ 30,000$ per month, a huge problem for patients. Oncologists worry about the rising costs of cancer treatment, in the USA there has been a 100-fold increase in cost per patient over the last 50 years.

The recent clinical trial with agents based on IBC and EGCG shows huge promise

\section{..therapy with I3C and EGCG in}

advanced ovarian cancer dramatically increased median overall survival by one and a half times and 5-year overall survival increased from $37 \%$ to $67 \%$.

visible tumours. This was not the case in to afford effective anti-cancer treatments. the control patients who hadn't received A fresh understanding of the biology the maintenance treatment. The scientists of ovarian tumours has allowed believe that this radical tumour removal Academicians Lev Ashraphyan and important for improvement of treatment Vsevolod Kiselev and their colleagues outcomes is due to the anti-tumour to develop a promising, effective, safe effects of 13 C and $E G C G$, including their and affordable treatment to tackle the ability to kill CSCs. formidable ovarian cancer. In the future Prolonged treatment with I3C and EGCG $\quad$ it's possible these results may be used showed a measurabi improvement treatment approaches for oth salfficit in the patient's quality of life and their $\quad$ to treat cancers.

\section{Behind the Research}

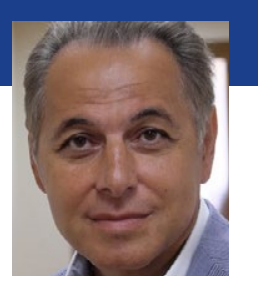

Lev Ashraphyan

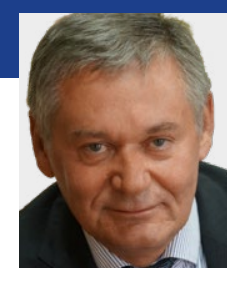

Vsevolod Kiselev E: vkis10@mail.ru

T: +7 495 765-87-87 (19-74) W: http://ncagp.ru/

\section{Detail}

\section{Bio}

Lev Ashraphyan:

A highly regarded gynaecologic oncologist and a surgeon Federation Dic cancrs, Hon Mammology of Acad VIKKulakov National Medicalogy and Centre of Obstetrics, Gynecology and Perinatology, the Ministry of Health of Russia (Moscow). Academician of the Russian Academy of Sciences, Professor, MD. A member of Russian and foreign Associations of gynecologists and gynecologic oncologists, President of Russian Association of specialists in the treatment of female reproductive system tumours.

\section{Vsevolod Kiselev:}

A highly regarded clinician-scientist, specialist in molecular biology, molecular medicine and biotechnology. Deputy Director, Institute of Gynaecologic Oncology and Mammology of Acad. VI. Kulakov National Medical Research the Ministry of Health of Russia (Moscow). Associate academician of the Russian Academy of Sciences, Professor D. Biol. Sci. Twice winner of Russian Government Award in Science and Engineering, a laureate of the Internation Prize to the best doctors of Russia "Vocation".

\section{Ekaterina Muyzhnek:}

Chief Scientific Officer Joint-Stock Company "IlmixGroup", Moscow, Russia. PhD (Biochemistry, Biol. Faculty,

M.V.Lomonosov Moscow State University). A winner of the Russian Academy of Medical Sciences Prize.

Gennady Sukhikh:

Honoured Scientist of the Russian Federation, Director, Obstetrics, Gynaecology and Perintology the Ministry of Health of Russia (Moscow) Academician of the Russian Academy of Sciences, Professor, MD.

\section{Collaborators}

- Evgeniya Gerfanova

- Olga Aleshikova (doctors who participated in this study)

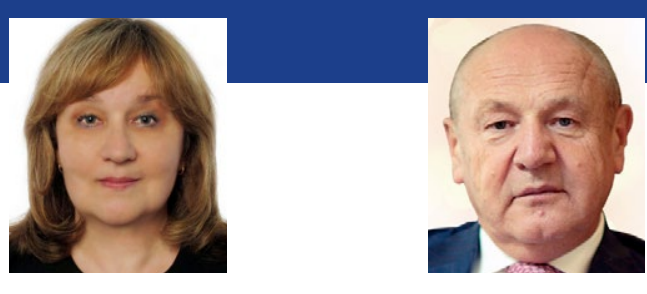

Ekaterina Muyzhnek Gennady Sukhikh E: MuyzhnekEL@ilmixgroup.ru
Research Objectives

The research is focused on an effective and safe approach of maintenance therapy for advanced ovarian cancer th

\section{References}

Kiselev V., Ashrafyan L., Muyzhnek E., Gerfanova E., Antonova Kiselev V., Ashrafyan L., Mayzhnek., Gerfanova E., Antonova of maintenance therapy in advanced ovarian cancer: a comparative clinical study. BMC Cancer 18:904.

\section{Personal Response}

How long will it take for this treatment to be available all people with ovarian cancer?

IU Welieve it depends on two points: the speed at would available information on this new treatment approach of oncologists (who are known as the most conservative clinicians) to accept current ideas and knowledge and their desire to apply them in clinical practice. But importantly, safety, attordability, simple peroral usage, in the trial could give a hope for a long happy life to lare number of oncological patients and their relatives with no participation of physicians if they aren't ready yet.
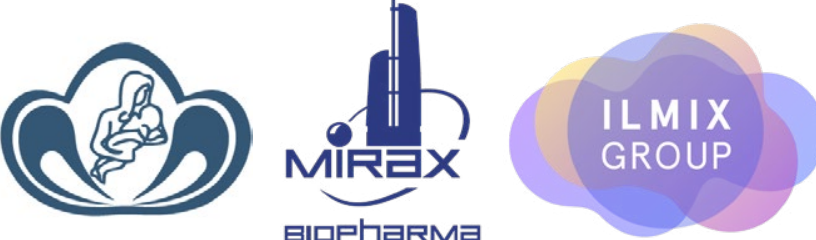